\title{
REMOTE SCREW-TYPE SYRINGE FOR SILICONE FLUID*†
}

\author{
BY \\ T. STUART-BLACK KELLY \\ Bath, Somerset
}

THE technique for the introduction of silicone fluid into the vitreous described by Cibis (1965) has certain difficulties. Considerable strength is needed to press the plunger home, and this may indeed be impossible unless the syringe is gripped by the hand and the plunger pressed by the thumb. This requires the hand to be presented to the eye in the reverse position to the normal, and while this makes for fairly accurate positioning of the needle, a sudden slip of the thumb might be disastrous. Further the slightest amount of silicone fluid on the outside of the syringe can make a satisfactory grip of the syringe almost impossible. Since indirect visual control is almost essential, any improvement in manual control would be helpful to a weaker hand.

Finally, the flow must be gentle and easily controlled, so that no jerking can nip off a globule or damage the all too adjacent retina.

\section{REQUIREMENTS FOR IMPROVEMENT}

(1) A needle independent of the syringe.

(2) Ease of accuracy of movement in introduction and mobility.

(3) A smooth flow, starting and ceasing when desired.

(4) Prevention of the fluid from spreading on the outside surface of the syringe.

\section{SUGGESTED IMPROVEMENT}

This is a screw-type syringe with a Luer lock end, connected by a lock to a strong plastic tube. This is tightly bound to the barrel of the lock to the syringe at one end, and to the barrel of the distant lock to the lock-type needle at the far end. The needles are a matter of personal preference, but No. $141^{1} \frac{1}{4}^{\prime \prime}$ has been found satisfactory, and is ground off flat and smooth at the tip, or blocked at the end, rounded off, with a side hole.

\section{METHOD OF USE}

(1) Filling the Syringe, Tube and Needle.-The cap of the syringe is unscrewed and the plunger is unscrewed up to the hilt, and both withdrawn together from the syringe. The silicone fluid is drawn up into a $5 \mathrm{ml}$. disposable syringe by passing the end of the syringe gently below the surface, so that no bubbles are made, or it is poured into a disposable syringe, the plunger having been removed.

- Received for publication March 30, 1967.

† Address for reprints: Linden, Weston Rd., Bath, Somerset. 


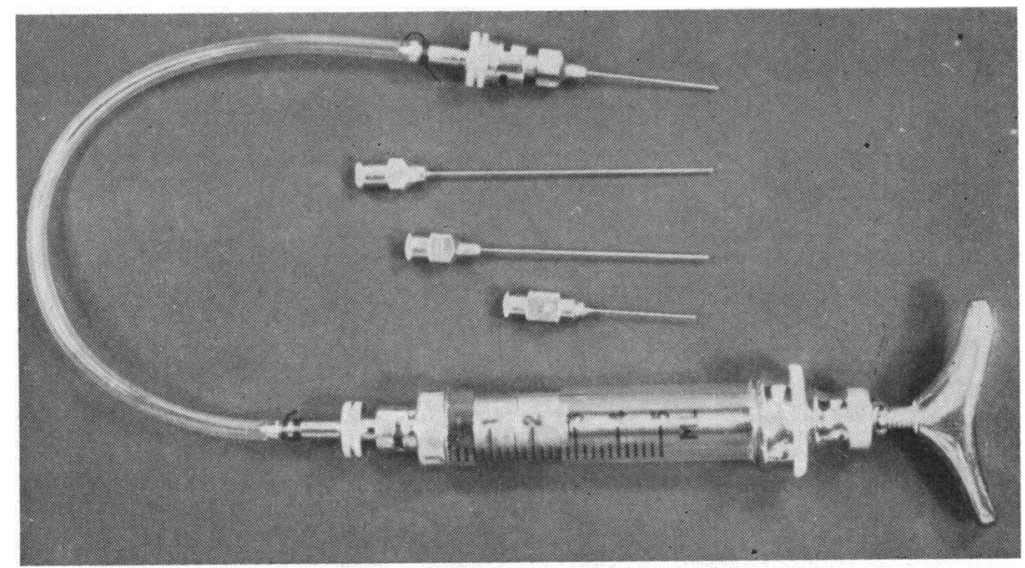

The fluid is now passed into the screw-type syringe from the syringe that has sucked up the fluid. The screw-type is held vertically by the assistant, and the needle on its plastic tubing, now connected to the syringe, is held up parallel and level, so that fluid does not pass straight through and run out. This procedure cuts surface spread to a minimum.

The assistant inserts the plunger, screws up the head, and slowly inverts the syringe, allowing all air to pass slowly to the top. The needle is now raised vertically above the syringe and the plunger screwed home until all the air has passed upwards out of the syringe and the tube and the needle. A single turn back of the screw will now stop the flow.

(2) Injection into the Vitreous.-When ready for insertion, the needle is lowered to enter the eye while at the same time a half-turn back is made to prevent any flow-otherwise the flow will commence as soon as the needle enters the vitreous, causing confusion both to the surgeon at the time and the patient later (for the fluid is optically clear) by extending a bubble too far forward which may never mix with the large posterior bubble, and may also affect the lens. The needle is passed in the normal way into the vitreous by the first and second fingers and thumb, holding the entire upper end of the needle and lock, through a prepared incision. Once it has reached its correct position, the assistant is instructed to start screwing. He keeps on screwing until he is instructed to stop, so that no separate globules come from the syringe. On the instruction to stop he gives one half-turn backward. It is advisable to inject all that is required at the one site.

The method has been found simple and easy to use, allowing direction beneath superior and inferior bulges of the retina when lying in contact with each other, and only a small gap showing in the flat funnel above the disc.

It is interesting to note that the early silver hypodermic syringes were made with a similar screw to grade the dose!

The syringe is made and supplied by Martindale Samoore Ltd., Salem Rd., Queensway, London, W.2., and may also be obtained from C. Davis Keeler Ltd., 21 Marylebone Lane, London, W.i.

\section{REFERENCE}

CibIS, P. A. (1965). “Vitreoretinal Pathology and Surgery in Retinal Detachment”. Mosby, St. Louis. 